\title{
ERRATUM
}

doi:10.1038/nature08165

\section{Self-assembly of DNA into nanoscale three-dimensional shapes}

Shawn M. Douglas, Hendrik Dietz, Tim Liedl, Björn Högberg,

Franziska Graf \& William M. Shih

\section{Nature 459, 414-418 (2009)}

In this Letter, Figure 3 was printed incorrectly. The corrected figure is presented below.

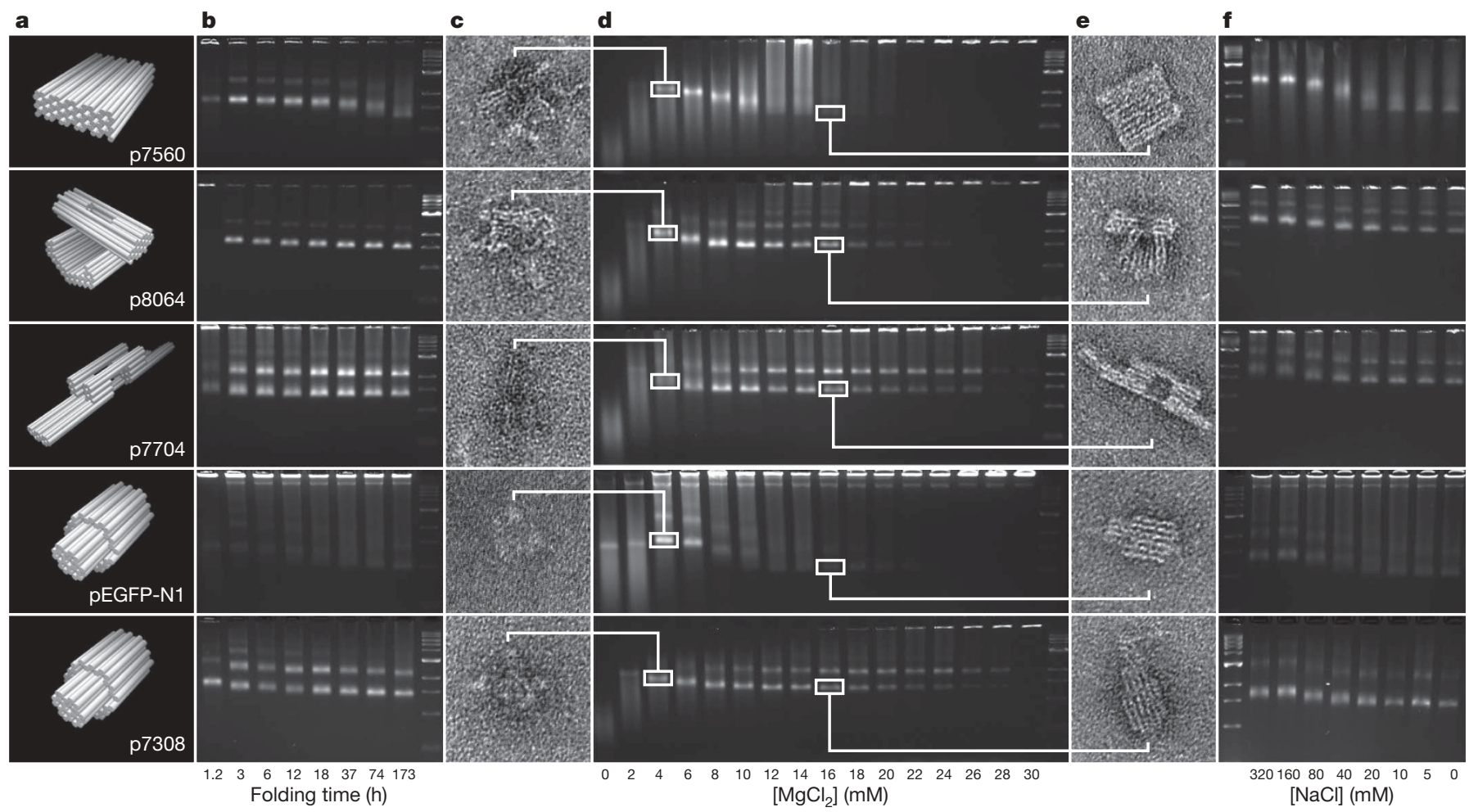

